\title{
Investigação sobre as relações interinstitucionais e interdisciplinares para o planejamento integrado de recursos hídricos na bacia hidrográfica do Rio Gramame, Brasil
}

Research on interinstitutional and interdisciplinary relations for the integrated planning of water resources in the Gramame River Basin, Brazil

Mirella Leôncio Motta e Costa ${ }^{1 *} \oplus$, Tarciso Cabral da Silva ${ }^{2} \oplus$, Maria Camerina Maroja Limeira ${ }^{2} \odot$

\section{RESUMO}

O entendimento das relações interinstitucionais existentes no sistema de recursos hídricos é um aspecto relevante para a identificação de lacunas e conflitos, bem como para a adoção de estratégias para a busca por um planejamento integrado de recursos hídricos. Nessa perspectiva, foi analisado o planejamento de recursos hídricos já efetuado na bacia hidrográfica do Rio Gramame, localizada no litoral sul do estado da Paraíba, Brasil. Para consecução do objetivo, foi utilizada a ferramenta metodológica análise de constelação, construída por um grupo focal composto de especialistas, tendo como alvo a interdisciplinaridade. como resultados, observou-se a fraca integração interinstitucional entre os órgãos responsáveis pela gestão da água e demais recursos naturais existentes na bacia hidrográfica, em função principalmente da baixa capacidade financeira, técnica e política para efetivação de suas competências. Em relação aos instrumentos de gestão, o mais citado e relacionado foi o enquadramento dos corpos hídricos em classes de uso preponderantes, sobretudo pela sua possível influência na melhoria qualitativa da água, quando implantado. O conjunto de elementos analíticos permite visualizar o potencial interinstitucional favorável à realização de um planejamento integrado de recursos hídricos na bacia hidrográfica, embora se enfrentem ainda muitas barreiras sociopolíticas para a tomada de decisão de maneira compartilhada.

Palavras-chave: análise de constelação; gestão de recursos hídricos; integração institucional; interdisciplinaridade; bacia hidrográfica do Rio Gramame.

\begin{abstract}
The understanding of the interinstitutional relations existing in the water resources system is a relevant aspect for the identification of gaps and conflicts, as well as for the adoption of strategies for the search for an integrated planning process. In this perspective, the planning of water resources already carried out in the hydrographic basin of the Gramame River, located on the southern coast of the state of Paraiba Brazil, was analyzed. The methodological tool of Constellation Analysis was used, built by a focus group composed of specialists, looking for the interdisciplinarity to reach the goal. As a result, there was a weak interinstitutional integration between the bodies responsible for the management of water and other natural resources existing in the river basin, mainly due to the low financial, technical, and political capacity to implement their competencies. Concerning management instruments, the most cited and related was the framing of water bodies in preponderant classes of use, mainly due to their possible influence on the qualitative improvement of water, when implemented. Regarding the management instruments, the most cited and related was the framing of water bodies in prevailing classes of use, mainly for their possible influence on the qualitative improvement of water, when implemented. The set of analytical elements allowed the visualization of the interinstitutional potential favorable to the realization of integrated planning of water resources in the hydrographic basin. However, there are still many socio-political barriers to shared decision making.
\end{abstract}

Keywords: constellation analysis; water resources management; institutional integration; interdisciplinarity; Gramame river basin.

IInstituto Federal de Ciência, Educação e Tecnologia da Paraíba - João Pessoa (PB), Brasil. ¿Universidade Federal da Paraíba - João Pessoa (PB), Brasil.

*Autora correspondente: mirellamotta@yahoo.com.br

Conflitos de interesse: os autores declaram não haver conflito de interesses.

Financiamento: nenhum.

Recebido: 17/O4/2019 - Aceito: 11/O2/2O2O - Reg. ABES: 20190119 


\section{INTRODUÇÃO}

Em todo o mundo, o planejamento de recursos hídricos ainda não tem sido contemplado de forma sistêmica. Ou seja, as questões socioeconômicas e ambientais não são tratadas integradamente. Diversas definições ainda são usadas de modo inconsistente ou incorreto. Muitas vezes, as previsões para o uso da água são feitas com premissas inadequadas ou irregulares. Especialistas em água e formuladores de políticas muitas vezes não parecem compreender o papel do uso da água nas políticas relacionadas com esse recurso. Os processos de planejamento evoluem não apenas para atender a novas demandas, expectativas e objetivos, mas também em resposta a novas percepções de como planejar e gerenciar os recursos hídricos de maneira mais eficaz (COSGROVE; LOUCKS, 2015; LOUCKS; BEEK, 2017).

No passado, o planejamento de recursos hídricos baseava-se em um enfoque setorial e fragmentado por setores usuários, cuja administração ocasionava conflitos crescentes, uso ineficiente de recursos e a sua consequente degradação. A partir da década de 1960, teve início um despertar mundial em busca de um novo modelo de gestão de águas, que passou a ser denominado de gestão integrada dos recursos hídricos (CAMPOS, 2013). Atualmente, o que se observa é a tentativa de planejamento de recursos hídricos compatibilizando os usos com as demandas, buscando a integração com as áreas econômica, social, cultural, de utilização do solo, costeira e gestão ambiental, ancorada na negociação social.

Ou seja, não basta considerar o planejamento dos recursos hídricos como uma ação voltada apenas para o âmbito da gestão dos recursos hídricos. Torna-se necessário integrar o planejamento dos recursos hídricos e o planejamento do desenvolvimento socioeconômico e ambiental, de modo a intervir de forma adequada nos planejamentos global, setorial e regional, com os inevitáveis reflexos na política de ordenamento do território.

A necessidade de elevar o planejamento dos recursos hídricos ao nível de planejamento sustentável, diante da forte interação dos recursos hídricos com os aspectos socioeconômicos na bacia hidrográfica, atrelada à indispensabilidade de manutenção das funções do meio ambiente e à essencialidade de integrar as populações nesse planejamento, levou ao surgimento do conceito de planejamento integrado de recursos hídricos.

O planejamento e a gestão integrada dos recursos hídricos em uma bacia hidrográfica devem destacar os usos múltiplos e seus propósitos, considerando a gestão econômica e os objetivos sociais e ambientais. Devem envolver tanto a relação com outras áreas e diferentes níveis de governo, como também demais partes interessadas, com vistas a um processo de tomada de decisão minimizando os conflitos.

A integração da gestão hídrica, com suporte no planejamento da bacia hidrográfica, deve ser efetivamente implantada e avançar para um processo de gestão ambiental de toda a bacia hidrográfica (LEAL, 2012; ZILIO et al., 2019). No entanto a gestão integrada, embora com algumas iniciativas em andamento, ainda não é realidade nas bacias hidrográficas brasileiras, possivelmente em função da dificuldade de realizar ações compartilhadas entre os órgãos gestores/reguladores ou por implantação de projetos descoordenados entre eles.

Nesse sentido, Pagnoccheschi (2016) alerta para preocupações relativas à gestão integrada dos recursos hídricos, como as assimetrias entre os setores usuários que podem criar situações irreversíveis, comprometendo o uso múltiplo dos recursos hídricos, premissa da legislação que orienta a temática. Isso deriva do fato de que os setores usuários de recursos hídricos trabalham com horizontes de planejamento muito diversos, segundo o propósito de suas intervenções e a capacidade técnica instalada. O setor elétrico, por exemplo, por força da magnitude dos investimentos necessários, do longo tempo de maturação exigido por seus empreendimentos e da capacidade técnica instalada em suas subsidiárias e coligadas, trabalha com grande antecedência, quando comparado com setores como o de transporte fluvial.

Para trabalhar com sistemas complexos e não lineares, o enfoque teórico deve recorrer a uma abordagem sistêmica e, ao mesmo tempo, holística do desenvolvimento sustentável, de modo a lidar com múltiplas dimensões em interações dinâmicas e de alto grau de incerteza. As relações entre a natureza e a sociedade devem ser percebidas como uma totalidade complexa formada de elementos constitutivos - subsistemas - integrados e interligados, estabelecendo entre si controles e restrições, cuja interação resulta no todo (BUARQUE, 2008).

Diante do exposto, este artigo trata da investigação sobre a existência das relações interinstitucionais e interdisciplinares no processo de construção do planejamento integrado de recursos hídricos na bacia hidrográfica do Rio Gramame, na região do litoral sul do estado da Paraíba. A técnica metodológica utilizada neste trabalho, a análise de constelação, tem se mostrado eficiente para visualizar problemas multidimensionais por meio de visão multidisciplinar, na medida em que permite enxergar o problema central e suas relações, a fim de obter soluções convergentes.

\section{METODOLOGIA}

\section{A técnica da análise de constelação}

A análise de constelação é uma metodologia criada por pesquisadores alemães que consiste numa ferramenta de análise de relações interinstitucionais, interdisciplinares e transdisciplinares utilizada para gestão de estudos de tecnologia, sustentabilidade e inovação (OHLHORST; KRÖGER, 2015).

De acordo com Kröger, Rückert-John e Schäfer (2012), a análise de constelação pode ser aplicada a várias disciplinas e práticas relevantes e tem a finalidade de obter perspectivas convergentes e aprendizagem conjunta sobre um assunto ou questão durante o processo de entendimento do problema. A ferramenta pode ser empregada para análise de problemas complexos ou para o desenvolvimento de soluções. Além disso, Ohlhorst e Kröger (2015) afirmam que a análise de constelação pode ser útil para uma pesquisa não apenas para seus problemas de interesse puramente científicos, mas para contribuir na resolução de problemas sociais.

Como um conceito-ponte, a análise de constelação oferece uma maneira de compreender categorias analíticas às quais diferentes disciplinas podem se relacionar, conectando-as. Além disso, pode ser usada como um instrumento autorreflexivo que ajuda a entender a evolução de projetos haja vista diferentes perspectivas disciplinares, unindo as culturas científicas (FELDHOFF et al., 2019).

Ao colocar pioneiramente a técnica da análise de constelação em prática, Schön, Nölting e Meister (2004) propuseram a divisão em quatro etapas: mapeamento, descrição, caracterização e análise. Essas etapas não são consecutivas, mas interativas e interligadas aos processos, podendo ser executada várias vezes, em sucessão ou paralelamente, uma vez que a descrição empírica e a construção e interpretação dos fatos estão juntas.

A metodologia da análise de constelação utiliza quatro diferentes tipos de elemento e suas relações, que são identificados por meio da literatura acadêmica, de peritos e das partes interessadas, mediante entrevistas, discussões em grupo 
e workshops. Esses tipos são modificados de forma contínua, constituindo-se, assim, em um processo interativo.

Para sua aplicação, é necessário que se identifiquem esses quatro tipos de elemento que compõem a constelação:

- atores (personalidades individuais, organizações, instituições públicas e privadas, organizações não governamentais e outros);

- elementos técnicos (objetos técnicos, equipamentos, estruturas);

- símbolos (ideias, conceitos, ideologias, leis, ações políticas e sociais e imagens);

- elementos naturais (substâncias e recursos - ar, água, terra -, animais e plantas, bem como fenômenos naturais, como secas, cheias e terremotos).

Tais elementos são interligados conforme as relações existentes entre eles, de acordo com a simbologia presente no Quadro 1.

Rodorff et al. (2013) propõem um passo a passo para a aplicação da metodologia:

- pré-estudo: revisão da literatura, primeiras visitas a instituições, questionários interdisciplinares e divisão do contexto em categorias e constelações iniciais;

- estudo básico: viagens de campo, intercâmbio transdisciplinar e entrevistas em diferentes níveis de governança, grupos de discussão e oficinas interdisciplinares da constelação;

- análise: análise das relações, das lacunas, das coalizões, dos conflitos criação de fenômenos -, novas visualizações da constelação e oficinas de constelação;

- próximos estudos: várias análises da constelação e discussões de outras inovações do projeto, intercâmbio transdisciplinar avançado, para apoiar o processo decisório.
Durante a aplicação da metodologia, a estratégia inicial é a formulação de uma pergunta orientadora de análise e descrição dos fenômenos (KRÖGER; RÜCKERT-JOHN; SCHÄFER, 2012). Durante os grupos de discussão, a constelação vai sendo construída, de forma artesanal e coletiva (com colaboração de stakeholders e especialistas), utilizando-se instrumentos visuais como tarjetas. Em momento posterior, as constelações são digitalizadas, obedecendo às cores e formas de cada categoria de elemento (Figura 1).

É importante salientar que o método não fica completo sem um texto explicativo que aprofunde as relações estabelecidas na análise, entendendo que a constelação se apresenta mais como uma ferramenta de síntese para a cooperação interdisciplinar no que se refere à compreensão do território analisado (MEDEIROS; GOMES; CAVALCANTE JUNIOR, 2014). Na etapa de análise a constelação é descrita textualmente. Ao ler a constelação, imagem e texto complementam-se: enquanto o mapeamento gráfico se concentra nos elementos e nas relações, a análise textual e a interpretação garantem maior ênfase na consideração da complexidade que existe na realidade.

Desde os trabalhos pioneiros de Schön, Nölting e Meister (2004), a análise de constelação já foi aplicada com sucesso em um grande número de projetos de pesquisa com diferentes temáticas, a partir da segunda década deste século, como os de Schäfer et al. (2010), Bruns e Ohlhorst (2011), Prantner (2012), Kröger, Rückert-John e Schäfer (2012), Burandt et al. (2013), Haack et al. (2014), Best (2015), Cunha (2016), Huesca-Pérez, Sheinbaum-Pardo e Köppel (2016) e World Overview of Conservation Approaches and Technologies (WOCAT, 2016). No Brasil, o Projeto Interplay Among Multiple Uses of Water Reservoirs Via Innovate Coupling Aquatic and Terrestrial Ecosystems (Innovate), que tinha como objetivo apontar a otimização dos múltiplos usos dos reservatórios artificiais no trecho submédio do Rio São Francisco, foi pioneiro ao utilizar essa metodologia, por intermédio dos trabalhos de Rodorff et al. (2013), Paula et al.

Quadro 1 - Relações e representações gráficas da análise de constelação.

\begin{tabular}{|c|c|c|}
\hline Relação & Representação & Características \\
\hline Simples & & Dois elementos estão simplesmente interligados \\
\hline Direcionada & & Um elemento atua sobre o outro \\
\hline Conflituosa & & Existem conflitos explícitos e intencionais entre dois ou mais elementos \\
\hline Resistência & & Indica resistência contra uma expectativa ou atribuição de outros elementos \\
\hline Incompatível & & Dois ou mais elementos são mutuamente incompatíveis \\
\hline Recorrente & & Dois elementos são inter-relacionados mutuamente intensificados \\
\hline
\end{tabular}

Fonte: adaptado de Rodorff et al. (2013) e Paula et al. (2014).

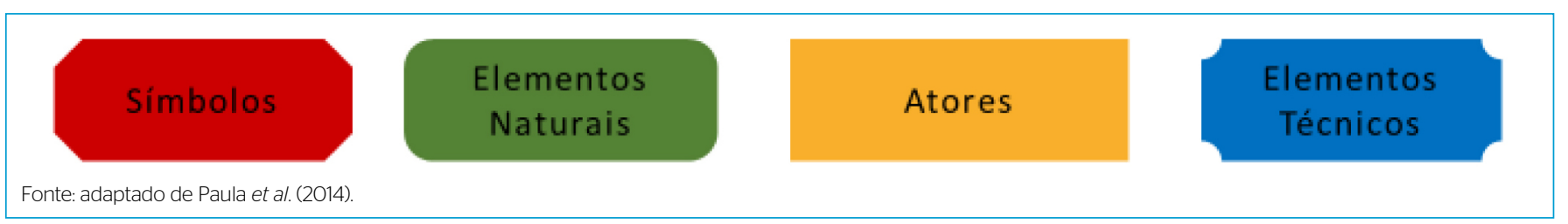

Figura 1 - Elementos e suas relações numa análise de constelação. 
(2014), Melo (2015), Siegmund-Schultze et al. (2015), Rodorff et al. (2015) e Rodorff et al. (2019), que demonstraram a sua aplicabilidade. Costa e Cabral da Silva (2016) desenvolveram uma revisão bibliográfica sobre a técnica da análise de constelação, em que são explicitados aspectos conceituais e metodológicos.

A justificativa para a escolha da análise de constelação na realização deste estudo se deu em decorrência da complexidade do tema planejamento integrado de recursos hídricos, o que impõe a necessidade de adotar-se uma abordagem integrativa associada à perspectiva de participação social interdisciplinar e interinstitucional, além do reconhecimento das relações que envolvem a água e as questões socioeconômicas e ambientais.

\section{O grupo focal e a construção da constelação}

O grupo focal é um grupo de discussão cujos objetivos são coletar informações e avaliar conceitos ou identificar problemas concernentes a um tópico específico, sugerido por um coordenador ou moderador do grupo, guiado por um conjunto de perguntas ligadas ao tema de trabalho. Foi a estratégia metodológica qualitativa utilizada para a construção da constelação.

Para este trabalho, os especialistas foram convidados por e-mail para participar do grupo focal e receberam antecipadamente um diagnóstico sintético com as características socioeconômicas e ambientais da área de estudo - a bacia hidrográfica do Rio Gramame. O conhecimento disciplinar sobre a bacia dos participantes do grupo focal definiu o período histórico analisado, que se inicia no processo de redemocratização e vai até os dias atuais.
Os especialistas convidados eram docentes e discentes de pós-graduação da Universidade Federal da Paraíba (UFPB), com formação disciplinar nas seguintes áreas: ciências biológicas, engenharia civil, administração, engenharia agrícola, engenharia sanitária e geografia. Os participantes do grupo focal também receberam o material de apoio, com os tipos de elemento e relações utilizadas na análise de constelação, bem como o material para elaboração da constelação (tarjetas coloridas e canetas).

A constelação foi construída de acordo com a seguinte questão orientadora: quais são os aspectos que interferem no planejamento integrado de recursos hídricos da bacia hidrográfica do Rio Gramame?

Ressalta-se que, além do grupo focal com especialistas, outros dados foram obtidos por intermédio da observação participante dos autores, em reuniões do Comitê das Bacias Hidrográficas do Litoral Sul (CBH-LS), no qual se inserem representantes de instituições e usuários da água da bacia hidrográfica do Rio Gramame. Somaram-se ainda as informações anteriormente coletadas em relatórios e documentos de instituições públicas, privadas e não governamentais, para, assim, contribuir na geração de diálogos entre os participantes do grupo focal e na interação com outros entrevistados em múltiplas instituições, nas diversas etapas da formação da constelação.

\section{A bacia hidrográfica do Rio Gramame}

A bacia hidrográfica do Rio Gramame está localizada no litoral sul do estado da Paraíba (Figura 2). Seus principais rios são o Rio Gramame, o Rio Mamuaba,

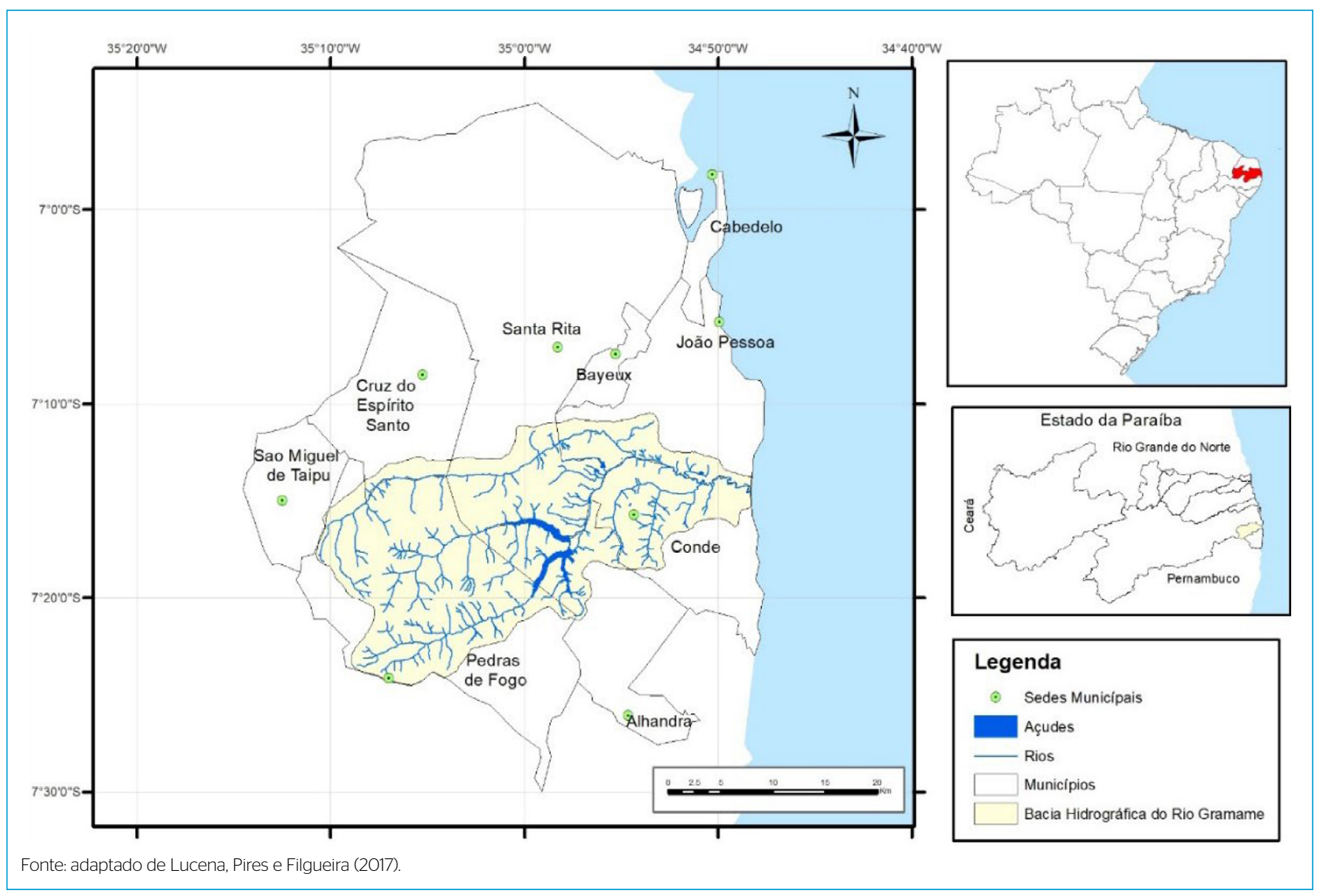

Figura 2 - Bacia hidrográfica do Rio Gramame. 
o Rio Mumbaba e o Rio Água Boa. Apesar de ser uma bacia de médio porte (área de $589,1 \mathrm{~km}^{2}$ ), possui um grande reservatório formado pela barragem Gramame-Mamuaba (com capacidade para 56,4 milhões $\mathrm{m}^{3}$ ), que é o principal responsável pelo abastecimento de mais de um milhão de habitantes dos municípios de João Pessoa, Cabedelo, Bayeux e Santa Rita. Em razão de outras particularidades observadas, julga-se que essa bacia hidrográfica é merecedora de considerações especiais, com diferenças físico-bióticas notórias quando comparada com outras bacias hidrográficas de seu porte, ou pelo alto grau de exploração antrópica a que está submetida.

Podem-se citar como as características socioeconômicas e ambientais mais marcantes dessa bacia hidrográfica: principal responsável pelo abastecimento de água de mais de um milhão de habitantes; presença em alto grau da exploração do solo pelas culturas da cana-de-açúcar e do abacaxi; presença de muitas indústrias de ramos diversos; existência de comunidades ribeirinhas dependentes do rio; e a atuação de diversos órgãos públicos que visam ao ordenamento do uso dos recursos naturais.

\section{RESULTADOS}

No Quadro 2, apresentam-se os elementos mencionados pelos especialistas, divididos em elementos naturais, símbolos, atores e elementos técnicos. Em termos quantitativos, os mais citados foram os atores (31), seguidos por elementos técnicos (24), símbolos (16) e elementos naturais (12).

$\mathrm{Na}$ Figura 3, observa-se a constelação construída pelo grupo focal com os especialistas. Na finalização da constelação, percebeu-se um grande emaranhado de elementos e relações, que tendem a indicar o comportamento das relações entre os elementos apontados pelo grupo focal.

\section{DISCUSSÃO}

Na elaboração da constelação, percebeu-se que os participantes trabalharam na criação de uma grande quantidade de elementos, que podem ser visualizados no Quadro 2 e na Figura 3. À primeira vista, observa-se um grande emaranhado de elementos e relações, em sua maioria positivas. As palavras em itálico apresentadas a seguir foram citadas na constelação pelos membros do grupo focal.

Nessa constelação, a água foi o elemento natural central, pois dela deriva a maior parte das relações com outros elementos. Alguns resultados indicaram que a água tem relações direcionadas com os seus usos múltiplos, lazer, pesca e mineração. Naturalmente, indicaram-se as relações entre água e elementos naturais como nascentes, área de preservação permanente (APPs) e estuário. Outras relações direcionadas foram entre água e atores, como as organizações não governamentais (ONGs) e o Ministério Público (refere-se ao Termo de Ajustamento de Conduta, celebrado entre os conflitantes com o Ministério Público). A água relacionou-se diretamente também com os instrumentos de gestão de recursos hídricos (cobrança, outorga, sistema de informações, plano de bacia hidrográfica e enquadramento). Foram indicadas algumas relações conflituosas, ou seja, quando determinado elemento interfere negativamente na qualidade ou quantidade de água, por existir graus de insatisfação para uma ou mais partes interessadas no uso da água. Os conflitos que envolvem o elemento água foram pertinentes a: monocultura (cana-de-açúcar), agrotóxicos, lançamento de efluentes industriais e saneamento básico deficiente.

Quanto aos usos, a atividade da pesca, totalmente dependente de água de boa qualidade, ocorre na barragem Gramame-Mamuaba e no baixo curso do Rio Gramame. Não foram indicados problemas associados à qualidade da água na barragem Gramame-Mamuaba para a atividade pesqueira. Já no baixo curso, a pesca conflita com a atividade das indústrias instaladas no distrito industrial que lançam seus efluentes no rio com tratamento insuficiente, tornando a água imprópria para a manutenção da vida aquática.

A poluição provocada pelo lançamento de efluentes do distrito industrial foi citada, pois impacta negativamente na atividade da pesca e também na saúde pública. Na bacia hidrográfica, a saúde pública também está em conflito com o saneamento básico deficiente, de responsabilidade da Companhia de Água e Esgotos da Paraíba (CAGEPA) e das prefeituras (nos aspectos de drenagem urbana e resíduos sólidos).

Não se ressaltou diretamente a relação entre água e abastecimento humano, embora ela seja evidente, uma vez que o uso para abastecimento de água

Quadro 2 - Elementos citados pelos especialistas durante o grupo focal.

\begin{tabular}{|l|l|}
\hline \multicolumn{1}{|c|}{ Tipos de elementos } & \\
\hline Elementos Naturais & Água, solo, nascentes, rios perenes, mata ciliares, clima/ar, vegetação, reserva legal, APPs, água subterrânea, fauna, estuário \\
\hline Símbolos & $\begin{array}{l}\text { Política Nacional de Recursos Hídricos, Política Estadual de Recursos Hídricos, sistema de informação, cobrança, outorga, crescimento populacional, } \\
\text { feira livre, feira orgânica, fiscalização, licenciamento ambiental, UCs, enquadramento, planos de recursos hídricos, CAR, PRAD, educação ambiental }\end{array}$ \\
\hline Atores & $\begin{array}{l}\text { Usuários, ANA, AESA, CBH-LS, CERH, SUDEMA, COPAM, IBAMA, agricultores orgânicos, Associação Agricultores Orgânicos, SEMA-MS, polícia florestal, } \\
\text { ONGs, Ministério Público, EVOT, agricultores familiares, distrito industrial, usina, prefeitura, INCRA, fornecedores de cana-de-açúcar, saúde pública, } \\
\text { Cagepa, EMATER, CREA, SENAR, IES, ASPLAN, SINDALCOOL, Sindicato dos Trabalhadores Rurais, SEIRHMACT }\end{array}$ \\
\hline Elementos técnicos & $\begin{array}{l}\text { Lançamento de efluente industrial, barragem Gramame-Mamuaba, agrotóxicos, fertilizantes, monocultura (cana-de-açúcar), uso do solo, usos } \\
\text { mugricultura da água, turismo, navegação, pesca, captação de água, coleta de resíduos sólidos, mineração, lazer, proximidade de João Pessoa (capital), } \\
\text { comunicação, núcleos urbanos }\end{array}$ \\
\hline
\end{tabular}

APPs: área de preservação permanente; UCs: unidades de conservação; CAR: Cadastro Ambiental Rural; PRAD: Plano de Recuperação de Área Degradada; ANA: Agência Nacional de Águas; AESA: Agência Executiva de Gestão das Águas da Paraíba; CBH-LS: Comitê de Bacias Hidrográficas do Litoral Sul; CERH: Conselho Estadual de Recursos Hídricos; SUDEMA: Superintendência de Administração do Meio Ambiente; COPAM: Conselho Estadual de Política Ambiental; IBAMA: Instituto Brasileiro do Meio Ambiente e dos Recursos Naturais Renováveis; SEMA-MS: Secretaria Estadual do Meio Ambiente do Mato Grosso do Sul; ONGs: organizações não governamentais; EVOT: Escola Viva Olho do Tempo; INCRA: Instituto Nacional de Colonização e Reforma Agrária; Cagepa: Companhia de Água e Esgotos da Paraíba; EMATER: Empresa de Assistência Técnica e Extensão Rural; CREA: Conselho Regional de Engenharia e Agronomia; SENAR: Serviço Nacional de Aprendizagem Rural; IEs: instituições de ensino federal e estaduais; ASPLAN: Associação dos Plantadores de Cana da Paraíba; SINDALCOOL: Sindicato das Indústrias Sucroalcooleiras; SEIRHMACT: Secretaria de Estado da Infraestrutura, dos Recursos Hídricos, do Meio Ambiente e da Ciência e Tecnologia. 


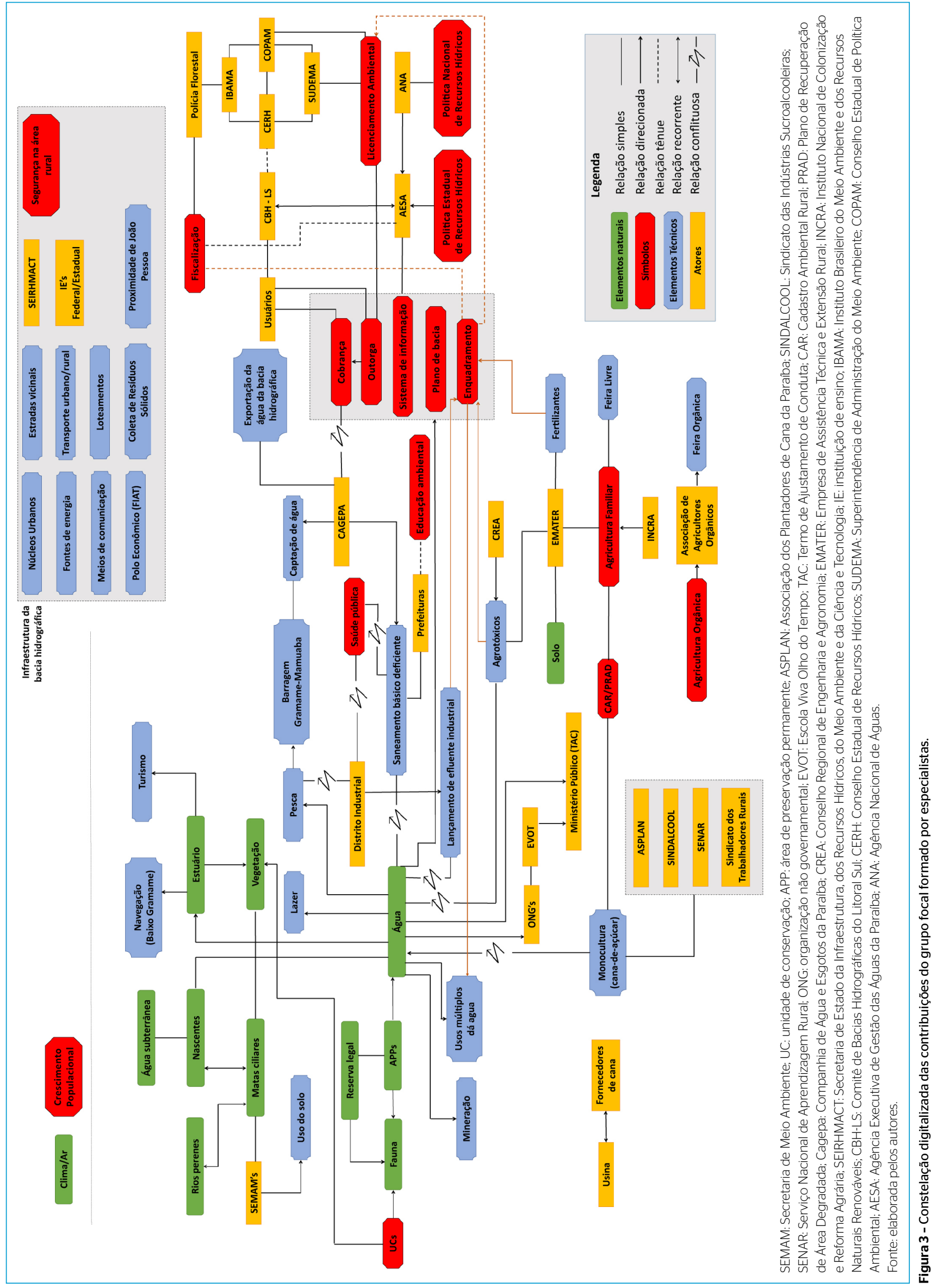


corresponde a 70\% do volume outorgado na bacia hidrográfica, em favor da CAGEPA. Essa relação foi citada por meio do elemento exportação da água da bacia hidrográfica, visto que a maior parte da água captada na bacia hidrográfica do Rio Gramame se destina ao abastecimento de sedes municipais que estão fora da área da bacia hidrográfica, como Cabedelo, Santa Rita e Bayeux.

Os participantes do grupo focal enfatizaram a presença da atividade monocultura de cana-de-açúcar como crítica para os recursos naturais da bacia hidrográfica, em função do empobrecimento do solo, do desmatamento na bacia hidrográfica para a realização da atividade e da utilização de agrotóxicos e fertilizantes nas lavouras. Ligadas ao setor sucroalcooleiro, foram citadas algumas instituições: Associação dos Plantadores de Cana da Paraíba (ASPLAN), Sindicato da Indústria de Fabricação do Álcool (SINDALCOOL), Serviço Nacional de Aprendizagem Rural (SENAR) e Sindicato dos Trabalhadores Rurais. No entanto os dois últimos não são relacionados apenas à cultura canavieira. Outros integrantes do setor da cana-de-açúcar são os fornecedores de cana (geralmente donos de terras que as arrendam para as grandes agroindústrias) e as usinas, todavia eles não foram ligados na constelação aos demais elementos desse setor.

Os especialistas disseram que os agrotóxicos trazem para a bacia hidrográfica uma relação conflituosa com a água e que isso se deve, entre outros, à falta de receituário agronômico, ou seja, à falta da prescrição e orientação técnica para utilização de agrotóxicos ou afim, por profissional legalmente habilitado (agrônomo), ou emissão da Anotação de Responsabilidade Técnica (ART) no Conselho Regional de Engenharia e Agronomia (CREA). Além disso, o impacto negativo dos agrotóxicos na água é decorrente da comercialização desses produtos ilegais, da venda clandestina (mesmo de produtos legalizados) e da aplicação sem técnica apropriada.

O Cadastro Ambiental Rural (CAR) e o Plano de Recuperação de Áreas Degradadas (PRAD) foram relacionados com a monocultura da cana-de-açúcar e com a agricultura familiar. O CAR e o PRAD são instrumentos da Política Nacional do Meio Ambiente (Lei Federal nº6.938/1981) e têm como objetivos diagnosticar as informações ambientais de propriedades rurais e, caso necessário, estabelecer um projeto de adequação do passivo ambiental, de modo a regularizar as áreas rurais no que tange à legislação ambiental vigente.

A Empresa de Assistência Técnica e Extensão Rural (EMATER) e o Instituto Nacional de Colonização e Reforma Agrária (INCRA) foram citados como órgãos auxiliares na manutenção da agricultura familiar na bacia hidrográfica, o primeiro fornecendo assistência técnica rural e o segundo realizando a distribuição de terras. Em toda a constelação, apenas a EMATER foi ligada ao elemento natural solo.

Foi apontada também a presença da atividade da agricultura orgânica na bacia hidrográfica e da associação de agricultores orgânicos, que comercializam seus produtos em feiras orgânicas promovidas em pontos específicos da bacia hidrográfica, entretanto tais elementos não foram conectados a outros elementos da constelação.

Um dos elementos (símbolos) considerados relevantes nessa constelação no que se refere aos corpos de água foi o enquadramento em classes segundo usos preponderantes, instrumento de gestão de recursos hídricos constante da Política Nacional de Recursos Hídricos (Lei no 9.433/1997). Ele relaciona-se com outros seis elementos: lançamento de efluente industrial, usos múltiplos da água, agrotóxicos, fertilizantes, licenciamento ambiental e fiscalização. Embora o enquadramento não seja efetivamente aplicado na gestão da bacia hidrográfica do Rio Gramame, os especialistas entendem a real necessidade de sua aplicação, em função do elevado grau de poluição dos corpos hídricos da bacia hidrográfica na porção contribuinte ao baixo curso do rio. A efetiva aplicação desse instrumento poderá levar a bacia hidrográfica a outro patamar de planejamento ambiental, no qual os empreendimentos adequariam suas atividades e o consequente uso da água (captação e lançamento de efluentes) à classe do corpo hídrico em que estariam enquadrados.

Os participantes do grupo focal não relacionaram os elementos naturais aos demais elementos da constelação, com exceção do elemento água. Enfatizaram a necessidade da preservação e recuperação ambiental, principalmente das matas ciliares e nascentes, mas não mencionaram os órgãos competentes (atores) para a sua execução.

Embora a Política Nacional do Meio Ambiente (Lei Federal nº.938/1981) não tenha sido citada, relacionou-se o licenciamento ambiental (instrumento da política ambiental), efetuado pela Superintendência de Administração do Meio Ambiente (SUDEMA), à outorga de direito de uso da água, que se conecta diretamente com a cobrança pelo uso da água, esses dois últimos como instrumentos de gestão constantes da Política Nacional de Recursos Hídricos.

O conflito indicado entre a CAGEPA e a cobrança pelo uso da água, que é executada pela Agência Executiva de Gestão das Águas do Estado da Paraíba (AESA), diz respeito à falta de pagamento do valor cobrado à CAGEPA, que resultava em R\$2,7 milhões, referente aos anos de 2015 e 2016. A CAGEPA alegava que estava revisando os valores cobrados em função das outorgas vigentes e da crise hídrica para, em seguida, efetuar o pagamento (CAGEPA, 2016). Sobre esse valor, incidem juros e multa caso a companhia não efetue o pagamento no prazo estabelecido. Os recursos provenientes da cobrança pelo uso da água nessa bacia foram cogitados para, em parte, ser destinados a projetos de restauração de áreas de proteção permanente por parte dos proprietários rurais que poderão apresentar o CAR e PRAD, de modo a atender às propostas de ação definidas em reuniões da diretoria do CBH-LS Dessa maneira, observou-se que as diferenças de tomadas de decisão, internas e externas, das instituições citadas dificultam ações compartilhadas que possibilitem gerar o planejamento integrado dos recursos hídricos nessa bacia hidrográfica. Em tempo, informa-se que o pagamento vem sendo efetuado desde janeiro de 2019.

O estuário do Rio Gramame foi relacionado, indicando certo conhecimento do grupo no que concerne à necessidade de integração da gestão das bacias hidrográficas com o sistema estuarino e a zona costeira. As relações indicaram haver conexão direta entre o estuário e a atividade de navegação (para pesca no baixo curso do Rio Gramame) e para o turismo.

As instituições participantes do sistema de gerenciamento de recursos hídricos, tais como CBH-LS, AESA, Agência Nacional de Águas (ANA) e Conselho Estadual de Recursos Hídricos (CERH), também foram pouco relacionadas aos demais. Os elementos que fizeram ligação com tais instituições foram a fiscalização, os instrumentos de gestão e as políticas nacional e estadual de recursos hídricos. A falta de relações desses atores com os demais elementos naturais, técnicos e símbolos da constelação indica haver ausência de integração do sistema de gestão de recursos hídricos com as demais políticas setoriais.

A relação existente entre a água e as ONGs, notadamente com a Escola Viva Olho do Tempo (EVOT) e o Ministério Público (TAC), foi bastante lembrada pelos especialistas como uma ação que tem aproximado o Ministério Público Federal do sistema ambiental e de recursos hídricos. Isso ocorre 
por meio de várias ações que visam combater todas as formas de poluição nas bacias hidrográficas do Litoral Sul (Abiaí e Gramame), pela interação entre instituições públicas e privadas e pelo permanente aprimoramento de órgãos e agentes das diversas esferas da administração pública com atuação no estado da Paraíba.

As relações tênues ocorreram entre as prefeituras e a educação ambiental, uma vez que a educação ambiental é realizada de maneira muito discreta na bacia hidrográfica; entre a fiscalização e o enquadramento, pois não é feita a checagem do alcance de metas progressivas ao longo do tempo; e entre a fiscalização e a $A E S A$, visto que essa agência governamental, destinada à gestão dos recursos hídricos no estado da Paraíba, está bastante deficitária em função da falta de recursos humanos.

Houve a introdução de elementos classificados pelos próprios participantes como de infraestrutura na bacia hidrográfica. Tais elementos foram sugeridos na constelação, mas não foram ligados aos demais no momento do estabelecimento das relações.

\section{CONCLUSÕES}

A análise de constelação elaborada pelos especialistas mostrou uma situação de integração entre os elementos citados, bem como forte interação entre os elementos técnicos e os atores. Foi percebida clara ênfase na caracterização diagnóstica da bacia hidrográfica do Rio Gramame, principalmente nos aspectos de poluição no baixo curso do Rio Gramame e no cultivo da cana-de-açúcar.

No aspecto interinstitucional, observou-se a fraca atuação dos órgãos responsáveis pela gestão da água e dos demais recursos naturais, em função principalmente da baixa capacidade financeira, técnica e política para efetivação de suas competências, tais como fiscalização, regularização, monitoramento, entre outras. Esses fatores, aliados à educação ambiental deficiente da população, que usa os recursos naturais de forma perdulária, contribuem para a situação de insustentabilidade ambiental da referida bacia hidrográfica, sobretudo no que se refere à qualidade dos corpos hídricos.

A lacuna de atuação dos órgãos responsáveis pelo controle ambiental na bacia tem motivado a atuação de órgãos externos ao sistema de gerenciamento de recursos hídricos, como os Ministérios Públicos Estadual e Federal, que têm buscado alternativas para reverter a situação de insustentabilidade ambiental da bacia hidrográfica por meio da instauração de um Inquérito Civil Público e da criação do Fórum Permanente de Proteção do Rio Gramame.

Todavia, a atuação de órgãos de controle externo, como os Ministérios Públicos, no sistema de gestão de recursos hídricos, com o objetivo de solucionar questões de uso e poluição da água, não constitui uma situação ideal e pode ser entendido como um indicativo de que o próprio sistema não está funcionando adequadamente.

Pode-se concluir que a melhor solução para reverter a situação de insustentabilidade da bacia passa pelas mãos da sociedade, dos atores envolvidos e dos órgãos responsáveis por sua gestão e seu ordenamento.

No que tange aos instrumentos de gestão, o mais citado e relacionado foi o enquadramento dos corpos hídricos em classes de uso preponderantes, de maneira especial pela sua possível influência na melhoria qualitativa da água, quando implantado.

O conjunto de elementos analíticos permitiu visualizar o potencial interinstitucional favorável à realização de um planejamento integrado de recursos hídricos na bacia hidrográfica. Todavia, houve o entendimento de que é necessário romper barreiras sociopolíticas para se tomar decisões de forma compartilhada.

O uso da ferramenta análise de constelação permitiu obter uma visão interdisciplinar sobre o objeto de estudo ao considerar as inter-relações e interdependências entre os elementos. Assim, foi possível realizar a análise integrada de um problema complexo, além da síntese e do consenso do conhecimento, da identificação de conflitos, bem como do desenvolvimento de estratégias para a sua resolução.

\section{AGRADECIMENTOS}

Os autores agradecem aos participantes do grupo focal a construção compartilhada da constelação.

\section{CONTRIBUIÇÕES DOS AUTORES}

Costa, M. L. M.: Conceitualização, Metodologia, Escrita - Primeira Redação, Escrita - Revisão \& Edição. Silva, T. C.: Conceitualização, Metodologia, Escrita — Primeira Redação, Escrita - Revisão \& Edição. Limeira, M.C.M.: Escrita — Primeira Redação.

\section{REFERÊNCIAS}

BEST, B. Nachhaltige Urbane Laboratorien. Transdisziplinäre Analyse der demokratischen ImplikationenvonEnergiewende-und Klimaschutzstrategien am Beispiel der InnovationCity Ruhr - Modellstadt Bottrop. Wuppertal Institut, 2015.

BRUNS, E.; OHLHORST, E. Wind Power Generation in Germany - a transdisciplinary view on the innovation biography. The Journal of Transdisciplinary Environmental Studies, v. 10, n. 1, 2011.

BUARQUE, S.C. Construindo o desenvo/vimento local sustentável: Metodologia de Planejamento. $4^{a}$ ed. Rio de Janeiro: Garamond Universitária, 2008.
BURANDT, A.; LANG, F.; SCHRADER, R.; THIEM, A. Working in Regional Agrofood Networks: Strengthening Rural Development through Cooperation. Eastern European Countryside, 2013.

CAMPOS, J.N.B. A gestão integrada dos recursos hídricos: Uma perspectiva histórica. Revista Eletrônica de Gestão e Tecnologias Ambientais, v. 1, n. 1, p. 111-121, 2013. https://doi.org/10.17565/gesta.vli1.7109

COMPANHIA DE AGUA E ESGOTOS DA PARAÍBA (CAGEPA). Ofício no 276/2016/PRE Referente ao Ofício no 03/2016 do FPCBH. Paraíba: CAGEPA, 2016. 
COSGROVE, W.J.; LOUCKS, D.P. Water management: Current and future challenges and research directions. Water Resources Research, v. 51, n. 6, p. 4823-4839, 2015. https://doi.org/10.1002/2014WR016869

COSTA, M.L.M.; CABRAL DA SILVA, T. Conceitos, metodologia e estudos sobre a técnica análise de constelação: uma revisão de literatura. Gaia Scientia, v. 10, n. 4, p. 497-515, 2016. https://doi.org/10.21707/gs.v10.n04a38

CUNHA, C.R.M. Relações institucionais do Sistema de Gestão de Recursos Hídricos do Estado da Paraíba: análise e proposições. Trabalho de Conclusão de Curso (Graduação) - Instituto Federal de Educação, Ciência e Tecnologia da Paraíba, João Pessoa, 2016.

FELDHOFF, B.; STOCKMANN, N.; FANDERL, N.; GAHLE, A.K.; GRAF, A.; LEGER, M.: SONNBERGER, M. Bridging Theories and Practices: Boundary Objects and Constellation Analysis as Vehicles for Interdisciplinary Knowledge Integration. Sustainability, v. 11, n. 19, p. 5357, 2019. https://doi.org/10.3390/su11195357

HAACK, F.; NAGEL, M.; RICHTERS, O.; SCHÄFER, E.; WUNDERLICH, S. Energieeffizienz \& Rebound-Effekte im Kontext der Energiewende. Abschlussbericht: Universität Oldenburg, 2014. 40 p.

HUESCA-PÉREZ, E.; SHEINBAUM-PARDO, C.; KÖPPEL, J. Social implications of siting wind energy in a disadvantaged region - The case of the Isthmus of Tehuantepec, Mexico. Renewable and Sustainable Energy Reviews, v. 58, p. 952-965, 2016. https://doi.org/10.1016/j.rser.2015.12.310

KRÖGER, M.; RÜCKERT-JOHN, J.; SCHÄFER, M. Inter- und transdisziplinäre Problembeschreibung im Projektverbund ELaN - Entwicklung eines integrierten Landmanagements durch nachhaltige Wasser- und Stoffnutzung in Nordostdeutschland. 2012.

LEAL, A.C. Planejamento ambiental de bacias hidrográficas como instrumento para o gerenciamento de recursos hídricos. Entre-Lugar, Dourados, v. 3, n. 6, p. 65-84, 2012.

LOUCKS, D.P.; BEEK, E.V. Water Resources Planning and Management: An Overview. In: LOUCKS, D.P.; BEEK, E.V. Water Resource Systems Planning and Management. Cham: Springer, 2017. p. 1-49.

LUCENA, A.P.D.; PIRES, A.L.; FILGUEIRA, H.J.A. Uso do IVDN no estudo da degradação ambiental da bacia hidrográfica do rio Gramame, Paraíba. Geociências, São Paulo, v. 36, n. 4, p. 755-769, 2017. https://doi.org/10.5016/ geociencias.v36i4.12752

MEDEIROS, M.L.; GOMES, M.B.; CAVALCANTE JUNIOR, E. Análise do território e das relações de produção no reassentamento de Icó-Mandantes em Petrolândia-PE. In: CONGRESSO BRASILEIRO DE GEÓGRAFOS, 7., 2014. Anais [...]. Vitória, 2014.

MELO, M.G.S. Modelagem multi-segmentar para governança de perímetros públicos de irrigação de base familiar no semiárido nordestino. Tese (Doutorado) - Programa de Pós-Graduação de em Engenharia Civil, Universidade Federal de Pernambuco, Recife, 2015.

OHLHORST, D.; KRÖGER, M. Konstellationsanalyse: Einbindung von Experten und Stakeholdern in interdisziplinäre Forschungsprojekte. In: NIEDERBERGER, M.; WASSERMANN, S. Methoden der Experten- und Stakeholdereinbindung in der sozialwissenschaftlichen Forschung. Wiesbaden: Springer Fachmedien Wiesbaden, 2015. p. 95-116.
PAGNOCCHESCHI, B. Governabilidade e Governança das Águas no Brasil. In: MOURA, A.M.M. (org.). Governança Ambiental no Brasil: instituições, atores e políticas públicas. Brasília, 2016. p. 175-199.

PAULA, J.; CARVALHO, R.M.; RODORFF, V.; SOBRAL, M.C. Análise de Constelação como instrumento do planejamento ambiental na gestão de recursos hídricos no Nordeste. In: SIMPÓSIO DE RECURSOS HÍDRICOS DO NORDESTE, 12., 2014. Anais [...]. Natal, 2014.

PRANTNER, M. Driving forces and barriers of electricity production from solid biomass in Hungary. An empirical example for a multilevel constellation analysis. In: INTERNATIONAL CONFERENCE ON SUSTAINABILITY. THEORY DEVELOPMENT \& CRITICAL PERSPECTIVES, 2012. Anais [...]. Alemanha: Wuppertal Institute for Climate, Environment and Energy, 2012. p. 310-337.

RODORFF, V:; ARAÚJO, G.J.; GOMES, E.T.; KÖPPEL, J.; SIEGMUNDSCHULTZE, M.; SOBRAL, M.C. Driving forces and barriers for a sustainable management of the Itaparica reservoir region - basic milestones towards a Constellation Analysis. In: GUNKEL, G.; SILVA, J.A.A.; SOBRAL, M.C. (org.). Sustainable Management of Water and Land in semiarid Areas: Case Study of the Itaparica Reservoir in Northeast Brazil. Recife: Editora Universitária UFPE, 2013. p. 265-279.

RODORFF, V.; SIEGMUND-SCHULTZE, M.; GUSCHAL, M.; HÖLZL, S.; KÖPPEL, J. Good Governance: A Framework for Implementing Sustainable Land Management, Applied to an Agricultural Case in Northeast-Brazil. Sustainability, v. 11, n. 16, p. 4303, 2019. https://doi.org/10.3390/su11164303

RODORFF, V:; SIEGMUND-SCHULTZE, M.; KÖPPEL, J.; GOMES, E.T. Governança da Bacia Hidrográfica do Rio São Francisco: desafios de escala sob olhares inter e transdisciplinares. Revista Brasileira de Ciências Ambientais, n. 36, p. 19-44, 2015. https://doi.org/10.5327/Z2176947820151003

SCHÄFER, M.; OHLHORST, D.; SCHÖN, S.; KRUSE, S. Science for the future: challenges and methods for transdisciplinary sustainability research. African Journal of Science, Technology, Innovation and Development, v. 2. n. 1, p. 114-137, 2010

SCHÖN, S.; NÖLTING, B.; MEISTER, M. Konstellationsanalyse. Ein interdisziplinäres Brückenkonzept für die Technik; Nachhaltigkeits- und Innovationsforschung. Discussion paper n. 12/04, jun. 2004.

SIEGMUND-SCHULTZE, M.; RODORFF, V.; KÖPPEL, J.; SOBRAL, M.C. Paternalism or participatory governance? Efforts and obstacles inimplementing the Brazilian water policy in a large watershed. Land Use Policy, v. 48, p. 120-130, 2015. https://doi.org/10.1016/j.landusepol.2015.05.024

WORLD OVERVIEW OF CONSERVATION APPROACHES AND TECHNOLOGIES (WOCAT). Análise de Constelação. WOCAT, 2016. Disponivel em: https:/qcat.wocat.net/wocat/approaches/view/ approaches_1974/. Acesso em: ago. 2017.

ZILIO, M.I.; SEITZ, C.; SCORDO, F.; GIL, V.; ZAPPERI, P.; COSTILLA, P., CISNEROS, M.A.H.; PERILLO, G.M.E.; PICCOLO, M. Is collaborative management always possible? The case of Sauce Grande River Basin, Argentina. International Journal of River Basin Management, v. 17, n. 2, p. 251-261, 2019. https://doi.org /10.1080/15715124.2018.1546727 